\title{
$\operatorname{cccccc}$ 論文Ｎi-Cr-Co 系合金スラッジを利用した電波吸収材料用 フェライトの水熱合成
}

\author{
黒木 俊 ${ }^{1}$ 小川 ひとみ ${ }^{2}$ 松 本 明子 ${ }^{2}$

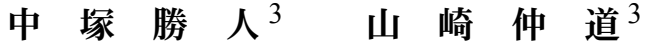

\section{Hydrothermal Synthesis of Ferrite from Ni-Cr-Co System Alloy Sludge for Electromagnetic Wave Absorption Materials}

by Toshihiro KUROKI ${ }^{\mathrm{a}}$, Hitomi OGAWA ${ }^{\mathrm{a}}$, Akiko MATSUMOTO ${ }^{\mathrm{a}}$, Katsuto NAKATSUKA ${ }^{b}$ and Nakamichi YAMASAKI ${ }^{\mathrm{b}}$

a. Research Institute of Technology, Konoshima Chemical Co., Ltd., Mitoyo-gun, Kagawa 769-1103, Japan

b. Graduate School of Engineering, Tohoku University, Aoba-ku, Sendai 980-8579, Japan

The synthesis of ferrite under hydrothermal conditions for electromagnetic wave absorption materials was investigated using the exhaust alloy sludge from the aircraft manufacturing. The alkaline suspension of precipitates containing $\mathrm{Ni}, \mathrm{Cr}$ and $\mathrm{Co}$ in sludge and $\mathrm{Fe}(\mathrm{II})$ was oxidized by the air bubbling at $25^{\circ} \mathrm{C}$ and treated under hydrothermal conditions at $170{ }^{\circ} \mathrm{C}$ for $8 \mathrm{~h}$. In the product at $\mathrm{pH} 12$, all the metal ions were incorporated excepting Mo into the spinel ferrite structure.

The formation of spinel ferrite structure was also attained easily by the Schikorr reaction at the comparatively low temperature. This method has the effective possibility for the synthesis of higher crystalline and large particle ferrite as compared with the traditional method, and also has the possibility for the production of higher saturation magnetization. This matter may be useful for the electromagnetic wave absorption materials.

The spinel type ferrite could be easily formed from the waste by using the mild hydrothermal conditions.

KEY WORDS : Spinel Ferrite, Waste Resource(Alloy Sludge), Hydrothermal Synthesis, Schikorr Reaction, Electromagnetic Wave Absorption

\section{1. 緒言}

近年情報関連機器の急速な発展により, GHz 帯域での電磁波の 利用が増大している。これに伴い，電磁波ノイズによる TV 受信 障害や無線 LANetc. の誤動作が生じている。これらを防止するた めに，スピネル型フェライトのような電波吸収材料が一般的に使

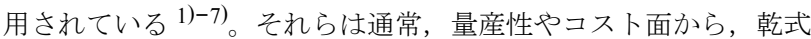
法によって合成されたものが主に使用されている。しかし，従来 の方法によって合成されたフェライトであっても，建築材料等に 広く使用するにはコストは高い。

これに対し，湿式法はフェライトの粒子径制御や化学組成の均 一性の面で優れており, 電波吸収材料として要求される組成や透 磁率等性能面での安定性を比較的容易に得ることが可能である。 そこで種々の分野で排出される有価金属を含有した廃棄物資源に 着目し，これをフェライト化することによって有価金属の回収を 計ると同時に，電波吸収材料としての適用の可能性について検討 するとことした。

種々金属イオンを含有するスピネル型フェライトの形成条件は 幾人かの研究者らによって詳細に検討されている ${ }^{8)-13)}$ 。しかしな

\footnotetext{
* 2001 年 6 月 4 日受付 9 月 25 日受理 資源 ・ 素材学会平成 13 年度春季大会 において一部発表 (2001 年 3 月 30 日)

1. 正会員 神島化学工業(株) 詫間工場技術研究所

2. 神島化学工業 (株) 詫間工場技術研究所

3. 正会員 工博 東北大学教授 大学院工学研究科地球工学専攻

[ 著者連絡先 ] FAX 0875-83-7074 (神島化学・技研)

E-mail : kuroki@konoshima.co.jp

キーワード : スピネルフェライト, 廃棄物資源, 水熱合成, Schikorr 反応, 電磁 波吸収
}

がら，種々の金属を含む廃棄物スラッジからのフェライト合成の 生成条件については，あまり検討されていない14)-16)。

ここでは 3 種類以上の金属イオンを含むスピネル型フェライト の水熱合成について, 空気酸化法を中心に種々金属イオンの沈殿 生成挙動や沈殿生成 $\mathrm{pH}$ および水熱処理による金属イオンの溶解 一沈積, ならびに生成物の飽和磁化について検討を行った。また, 共沈法と Schikorr 反応法についても比較検討を行った。

\section{2. 実 験 方 法}

出発合金スラッジは，航空機用合金として用いられている Ni$\mathrm{Cr}-\mathrm{Co}$ 系材料 ( 概略含量 ; $\mathrm{Ni}: 21 \mathrm{wt} \%, \mathrm{Cr}: 7 \%$, Co : $4.7 \%$, Mo : $1.1 \%, \mathrm{Ti}: 0.4 \%)$ の電解加工残涬である。これを溶解に必要な量 の 3 倍量の $6 \mathrm{~mol} / \mathrm{dm}^{3} \mathrm{HCl}$ を加え, 容量 $80 \mathrm{~cm}^{3}$ のテフロン製容器 中で $180{ }^{\circ} \mathrm{C}, 5$ 時間水熱処理し, 完全に溶解させた。硫酸第一鉄 $\left(\mathrm{FeSO}_{4} \cdot 7 \mathrm{H}_{2} \mathrm{O}\right)$ は, 合金スラッジ塩酸溶液中に加温溶解した。試 料溶液の濃度は, $\mathrm{Ni}, \mathrm{Cr}, \mathrm{Co}$ イオン計で $0.05 \mathrm{~mol} / \mathrm{dm}^{3}$ および $\mathrm{Fe}^{2+}$ イオン ( 共沈法の場合, $\mathrm{Fe}^{3+}$ ) で $0.11 \mathrm{~mol} / \mathrm{dm}^{3}$ とした。

試料溶液約 $60 \mathrm{~cm}^{3}$ を, $25^{\circ} \mathrm{C}$ で $\mathrm{pH} 12$ まで $1 \mathrm{~mol} / \mathrm{dm}^{3} \mathrm{NaOH}$ 溶液 (注入量 : $0.7 \mathrm{~cm}^{3} / \mathrm{min}$ ) を用いて中和を行い, $\mathrm{pH}$ 滴定曲線を得た。 その結果から, 沈殿挙動を検討するために $\mathrm{pH} 3.2,6.0$ および 10.6 にて沈殿物を調整した。それぞれのろ液の金属イオンは, 誘導結 合プラズマ分光法 (ICP-AES : SII SPS-1700VR) により分析した。 同時に $\mathrm{pH}$ の影響をみるために, $\mathrm{pH} 10,11,12$ および 13 で沈殿 物を調整した。これらのアルカリ性懸濁液は， $25^{\circ} \mathrm{C} ， 2$ 時間の空 気バブリング (空気流量 : $1.5 \mathrm{dm}^{3} / \mathrm{min}$ ) により酸化を行った。得 
られた沈殿物は遠心分離，洗浄した後，その水性懸濁液を $170{ }^{\circ} \mathrm{C}$, 8 時間の水熱条件で処理した。また，共沈法および Schikorr 反応 法の沈殿形成は $\mathrm{pH} 12$ で，水熱処理は前記と同一条件で行った。

沈殿物は X 線粉末回折法 (XRD : Rigaku Rint 2000, $40 \mathrm{kV} / 30$ $\mathrm{mA}, \mathrm{Cuk} \alpha$ ), 透過型電子顕微鏡 (TEM : JEOL JEM-100SX), エネ ルギー分散型 X 線分光法 (EDS : HORIBA EMAX-7000) および振 動試料型磁力計 (玉川製作所 : TM-VSM1230-HHHS)により評価し た。比表面積はBET 法 ( $\beta$ etasorb Model 4200) によって測定した。

\section{3. 実験結果および考察}

\section{$3 \cdot 1$ 沈殿の挙動}

単層および混合溶液の $\mathrm{pH}$ 滴定曲線を Fig.1 亿示す。混合溶液の $\mathrm{pH}$ 滴定曲線が 2 段になっているが, 最初の平坦部は主に $\mathrm{Cr}^{3+}$ の 沈殿に起因し， 2 段目は $\mathrm{Fe}^{2+}, \mathrm{Ni}^{2+}, \mathrm{Co}^{2+}$ の沈殿によるものであ る。次に，それぞれの $\mathrm{pH}$ での ICP 分析データを Table 1 に示す。 試料溶液中の各金属量に対し, pH3.2 では, Ni16\%, Co12\%, Fe11 \%, Mo98\%, Ti100\%が沈殿した。pH6.0 では, Ni42\%, Co32\%, $\mathrm{Fe} 28 \%, \mathrm{Cr}, \mathrm{Mo}, \mathrm{Ti} の 100 \%$ が沈殿した。また, pH10.6では, Mo イオンの少しの溶出を除き，すべての金属イオンが沈殿した。 これらの結果より，それぞれの金属イオンの沈殿は単体イオンの $\mathrm{pH}$ 滴定曲線と比較し，より低い $\mathrm{pH}$ で始まっている。この沈殿挙 動は, 他の金属イオンが初期段階において沈殿した共存イオンの 影響を受け，水酸化物やヒドロキシ硫酸塩 $\left(\mathrm{Me}(\mathrm{OH}) x\left(\mathrm{SO}_{4}\right) 2 y x+\right.$ $2 y=2)$ として共沈していることを示唆している。ヒドロキシ硫酸 塩の存在は, 神崎ら 10) によって確認され, ここでは単体金属イオ ン溶液中に 0.5 当量の $\mathrm{NaOH}$ を加えたときの溶存イオン量より逆 算すること, およびその沈殿物の XRD 分析により，推察した。

\section{$3 \cdot 2$ フェライトの結晶化}

各 $\mathrm{pH}$ での水熱処理生成物の XRD プロファイルを Fig.2 に示す。 pH10 および 11 では非晶質類似構造を示したが，pH12 および 13

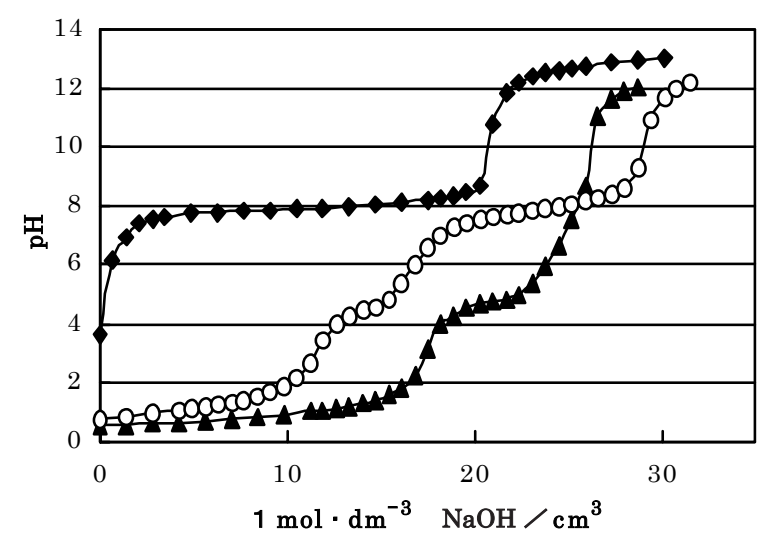

Fig.1 PH titration curves of the simple and mixed solutions. : ferrous sulfate $\boldsymbol{\Delta}$ : alloy sludge : alloy sludge + ferrous sulfate

Table 1 Amount of various metal ions in products at each $\mathrm{pH}$

\begin{tabular}{|c|c|c|c|c|}
\hline & \multirow{2}{*}{$\begin{array}{c}\text { Initial } \\
\text { concentration } \\
\left(\mathrm{mol} / \mathrm{dm}^{3}\right)\end{array}$} & \multicolumn{3}{|c|}{ Amount of various metal ions (\%) } \\
\hline & & $\mathrm{pH} 3.2$ & $\mathrm{pH} 6.0$ & $\mathrm{pH} 10.6$ \\
\hline $\mathrm{Ni}$ & 0.0315 & 16.4 & 42.3 & 100 \\
\hline Co & 0.0069 & 11.7 & 32.4 & 100 \\
\hline $\mathrm{Cr}$ & 0.0116 & 42.7 & 100 & 100 \\
\hline Mo & 0.0013 & 97.8 & 100 & 97.6 \\
\hline $\mathrm{Ti}$ & 0.0020 & 99.7 & 100 & 100 \\
\hline $\mathrm{Fe}$ & 0.1103 & 10.5 & 28.4 & 100 \\
\hline
\end{tabular}

ではスピネル構造のピークを示した。しかしながら, Fig.3に示す ように共沈法やSchikorr反応によって得られた生成物の XRD プロ ファイルは, これらの結果と比較するとよりシャープなスピネル のピークを示した。共沈法 (A) および Schikorr 反応 (B) は, 一般 的に次のような反応式で示される。

(A) $\mathrm{Fe}^{2+}+2 \mathrm{Fe}^{3+}+8 \mathrm{OH}^{-} \rightarrow \mathrm{Fe}_{3} \mathrm{O}_{4}+4 \mathrm{H}_{2} \mathrm{O}$

(B) $3 \mathrm{Fe}(\mathrm{OH})_{2} \rightarrow \mathrm{Fe}_{3} \mathrm{O}_{4}+\mathrm{H}_{2}+2 \mathrm{H}_{2} \mathrm{O}$

フェライト合成への Schikorr 反応の応用は, 既報 ${ }^{17)}$ で報告した が，ここでは廃棄物からのフェライト合成において, 従来の方法 と比較検討した。その結果, この実験の中で焼成法を除き, 最も 大きな粒子が得られ, その比表面積は約 $11 \mathrm{~m}^{2} / \mathrm{g}$ と小さかった。

また別の結果として, 過剩の Fe は水熱プロセスでは固溶体を形 成しているが，焼成法においては $\alpha \mathrm{Fe}_{2} \mathrm{O}_{3}$ として分離析出するこ とがわかった。

$3 \cdot 3$ 沈殿への pH の影響と水熱処理による各イオンの溶出 pH10，11，12 および 13 での ICP 分析データを Table 2 に示す。 空気酸化後, pH10, 11 では Ni, Co の 5 〜 \% が残存しているが, その他のイオンはほとんど $100 \%$ が沈殿物となった。pH12, 13 で はMoの $70 \sim 75 \%$ を除き, ほとんど $100 \%$ の金属イオンが沈殿 物として析出した。高 $\mathrm{pH}$ においては, $\mathrm{Mo}$ は $\mathrm{MoO}_{4}^{2-}$ として溶存

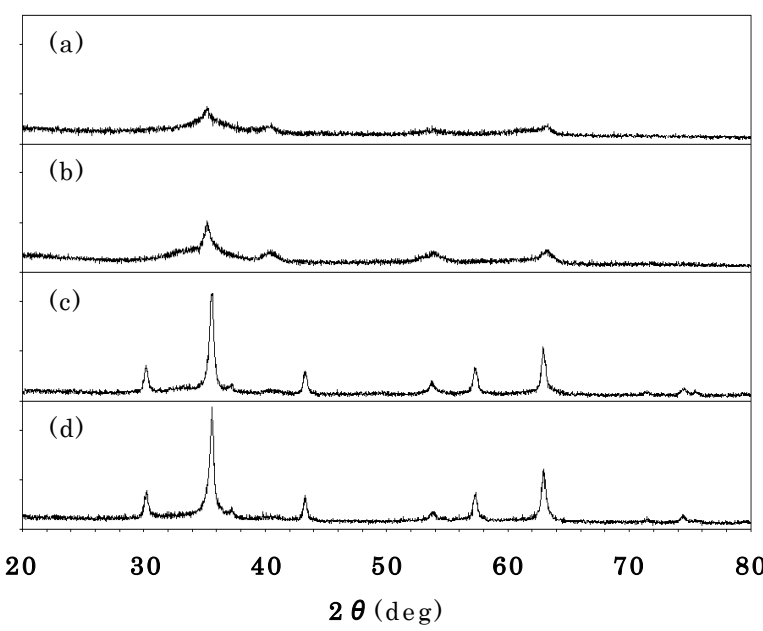

Fig.2 X-ray profiles of ferrites obtained by the hydrothermal method. The $\mathrm{pH}$ value in the initial suspension was (a) 10 , (b) 11 , (c) 12 and (d) 13 , respectively.

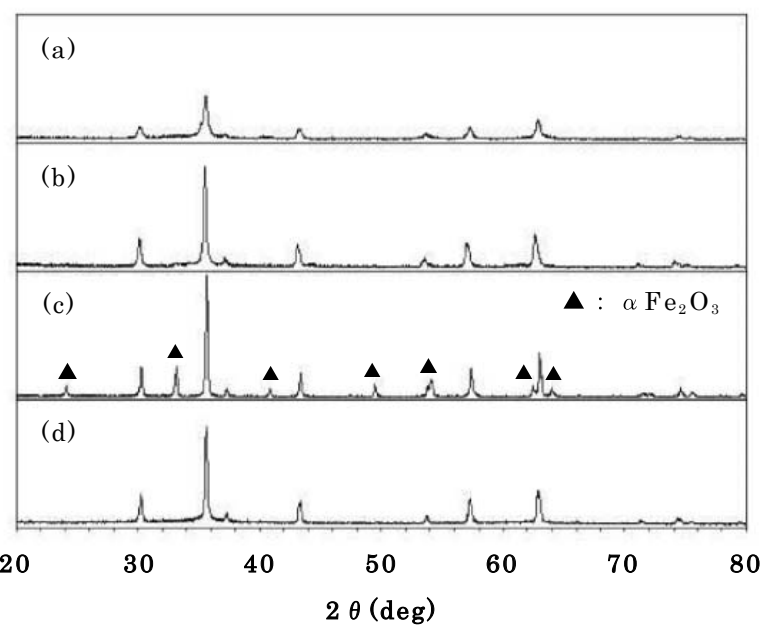

Fig.3 X-ray profiles of ferrites obtained by various production methods. (a) by air-bubbling and hydrothermal treatment

(b) by Schikorr reaction

(c) by air-bubbling and calcining at $1,000^{\circ} \mathrm{C}$ for $8 \mathrm{~h}$

(d) by coprecipitation and hydrothermal treatment 
Table 2 Amount of various metal ions in products at each $\mathrm{pH}$

\begin{tabular}{|c|c|c|c|c|c|c|c|c|c|}
\hline & \multirow{3}{*}{$\begin{array}{c}\text { Initial } \\
\text { concentration } \\
\left(\mathrm{mol} / \mathrm{dm}^{3}\right)\end{array}$} & \multicolumn{8}{|c|}{ Amount of various metal ions (\%) } \\
\hline & & \multicolumn{2}{|c|}{$\mathrm{pH} 10$} & \multicolumn{2}{|c|}{$\mathrm{pH} 11$} & \multicolumn{2}{|c|}{$\mathrm{pH} 12$} & \multicolumn{2}{|c|}{ pH13 } \\
\hline & & before & after & before & after & before & after & before & after \\
\hline $\mathrm{Ni}$ & 0.0315 & 94.6 & 93.7 & 98.8 & 96.8 & 100 & 100 & 100 & 100 \\
\hline Co & 0.0069 & 97.0 & 85.8 & 99.4 & 91.6 & 100 & 100 & 100 & 100 \\
\hline $\mathrm{Cr}$ & 0.0116 & 100 & 100 & 100 & 100 & 100 & 99.6 & 99.8 & 95.5 \\
\hline Mo & 0.0013 & 99.4 & 100 & 97.5 & 100 & 31.1 & 94.8 & 25.4 & 86.5 \\
\hline $\mathrm{Ti}$ & 0.0020 & 99.9 & 100 & 99.9 & 99.9 & 100 & 100 & 100 & 100 \\
\hline $\mathrm{Fe}$ & 0.1103 & 100 & 100 & 100 & 100 & 100 & 100 & 100 & 100 \\
\hline
\end{tabular}

していると推察される。水熱処理後においては, pH10，11 では少 量の $\mathrm{Ni}, \mathrm{Co}$ が, $\mathrm{pH} 13$ では $\mathrm{Cr}$ と Mo が溶出した。しかし, $\mathrm{pH} 12$ では Mo イオンを除き，ほとんど溶出は認められなかった。水熱 処理生成物の EDS プロファイルを Fig.4 に示す。この結果から, 各金属イオンは生成物中に均一に分散していることがわかった。

これらの結果より，この廃棄物資源系において，種々の金属イ オンを含有するスピネル型フェライトの形成には pH12 の条件が 好適であることがわかった。

\section{$3 \cdot 4$ 空気酸化による $\mathrm{pH}$ と電位の変化}

アルカリ性懸濁液の空気酸化による $\mathrm{pH}$ と電位 (微分值)の変化 をFig.5 に示す。その酸化反応は一般的には次のように示される。

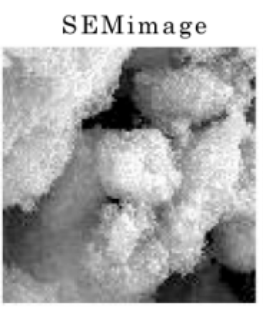

$\operatorname{CoK} \alpha$

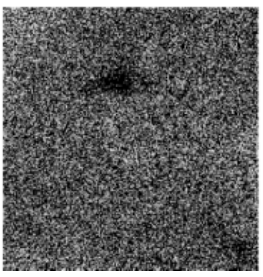

Fig.4 EDS profiles of ferrite obtained by air-bubbling and hydrothermal treatment at $170^{\circ} \mathrm{C}$ for $8 \mathrm{~h}(20,000 \times)$

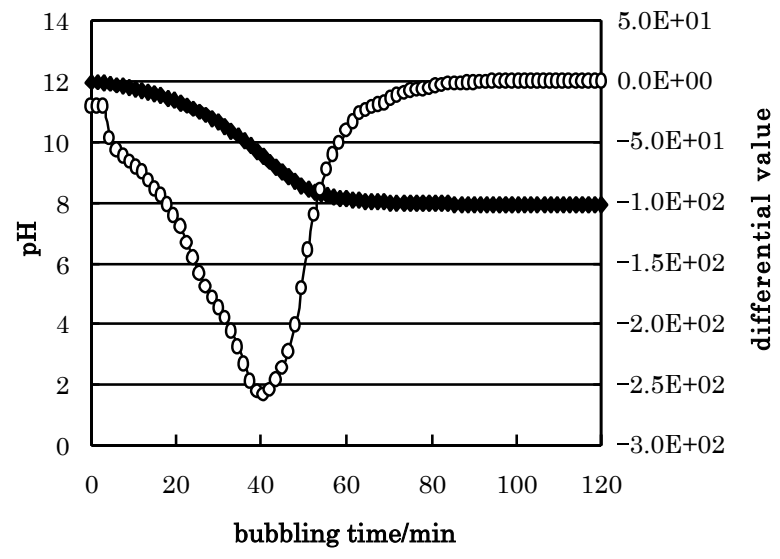

Fig.5 Change of the $\mathrm{pH}$ and potential by the air oxidation of alkaline suspension.

$\diamond: \mathrm{pH} \quad \bigcirc:$ differential value
$\mathrm{Me}_{\mathrm{x}} \mathrm{Fe}_{3-\mathrm{x}}(\mathrm{OH})_{6}+1 / 2 \mathrm{O}_{2} \rightarrow \mathrm{Me}_{\mathrm{x}} \mathrm{Fe}_{3-\mathrm{x}} \mathrm{O}_{4}+3 \mathrm{H}_{2} \mathrm{O}$

$\mathrm{pH}$ 值は酸化反応の進行とともに減少し, $\mathrm{Fe}^{2+}$ から $\mathrm{Fe}^{3+}$ 一の酸化 終了後, その $\mathrm{pH}$ 值は一定になった。

Fig.6 に種々製法の TEM 写真を示す。この図から, Schikorr 反 応によれば, 焼成法より小さいが約 $0.1 \mu \mathrm{m}$ の比較的大きい粒子が 得られることがわかった。一方, 通常の水熱法の生成物は微粒子 であった。ただし，共沈法では不定形のポーラスな粒子であった。 また, それらの飽和磁化測定データをTable 3 に示す。Schikorr 反 応生成物が $39.5 \mathrm{emu} / \mathrm{g}$ を示し, $\mathrm{Ni}$ フェライトの $50 \mathrm{emu} / \mathrm{g}^{18)}$ より は低いが，今回比較した合成法の中では最も高い值を示した。そ の他の生成物の飽和磁化が低い理由としては, 空気酸化法は粒径
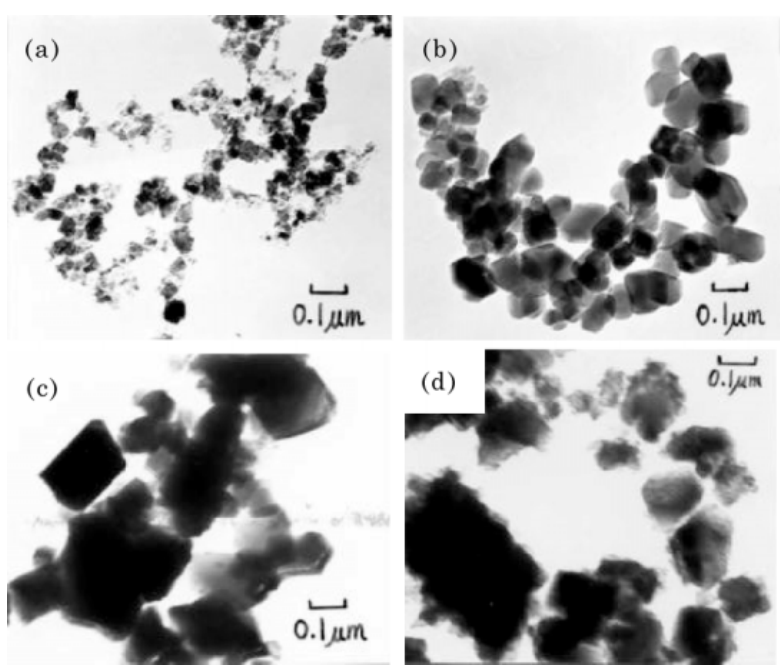

Fig.6 Electromicrographs of ferrites obtained by various production methods.

(a) by air-bubbling and hydrothermal treatment

(b) by Schikorr reaction

(c) by air-bubbling and calcining at $1,000^{\circ} \mathrm{C}$ for $8 \mathrm{~h}$

(d) by coprecipitation and hydrothermal treatment

Table 3 Saturation magnetization and BET value of ferrites obtained by various methods

\begin{tabular}{c|c|c}
\hline Method & Ms $(\mathrm{emu} / \mathrm{g})$ & BET value $\left(\mathrm{m}^{2} / \mathrm{g}\right)$ \\
\hline (a) & 16.8 & 127 \\
\hline (b) & 39.5 & 11.4 \\
\hline (c) & 29.5 & 3.8 \\
\hline (d) & 20.7 & 162 \\
\hline
\end{tabular}

(a) by air-bubbling and hydrothermal treatment

(b) by Schikorr reaction

(c) by air-bubbling and calcining at $1,000^{\circ} \mathrm{C}$ for $8 \mathrm{~h}$

(d) by coprecipitation and hydrothermal treatment 
が小さく, 結晶性も低いため, 共沈法では結晶性は良いが微粒子 (一次結晶粒子) であるため, また, 焼成法では粒径が大きく, 結 晶性も良いが，常磁性体である $\alpha-\mathrm{Fe}_{2} \mathrm{O}_{3}$ の分離析出の影響による ためと考えられる。

電波吸収材料として，一般的には透磁率の高い材料が良いとさ れているが，そのためには粒子径が大きく，結晶性の高いものが 必要である。透磁率と磁束密度は比例関係にあり, また, ソフト フェライト材料においては磁束密度と飽和磁化は同等とみなされ ているので, ここでは一つの指標として, 飽和磁化によって評価 した。これらの結果より, 廃棄物からのフェライト合成に Schikorr 反応を適用することによって, 結晶性が高く, より大きい粒子で 飽和磁化の高いフェライト合成の可能性があることがわかった。 したがって，このプロセスは電波吸収用フェライトの合成に有用 であると考えられる。

\section{4. 結言}

種々の金属イオンを含有する廃棄物スラッジから, 空気酸化 + 水熱法，空気酸化 + 焼成法，共沈法および Schikorr 反応法による スピネル型フェライト合成について比較検討した。

pH12 で得られた空気酸化・水熱処理生成物は, ICP, XRD およ びEDSによれば, Moイオン $(70 \%)$ を除いて $100 \%$ の金属イオン を均一に包含したスピネル型フェライトであることを確認した。

しかしながら, Schikorr 反応による廃棄物からのフェライト合 成への可能性についても示された。この製法は, 従来法と比較し
て結晶性が高く，大きな粒子の形成の可能性とともに，より高い 飽和磁化を有するフェライト合成が可能であった。この結果は電 波吸収材料として有用なフェライト合成の可能性を示唆している と思われる。

スピネル型フェライトは, 比較的マイルドな水熱条件を使用す ることによって, 容易に廃衰物より形成することができた。今後, 電波吸収特性についても検討を予定している。

\section{引用文献}

1) 清水康孝・杉浦 行 - 石野 健: 最新電磁波の吸収と遮蔽, 日経技術図書 (株), (1999)

2）橋本康雄：日本応用磁気学会誌，Vol. 16, No. 3, p. 175-178, (1982)

3) 古森秀樹 : Techno-Cosmos, Vol. 8, p. 10-16, Nov., (1995)

4) 古森秀樹 : Techno-Cosmos, Vol. 10, p. 24-29, Nov., (1996)

5) 杉本 諭・太田博康 : セラミックス, Vol. 34, No. 8, p. 638-642, (1999)

6）杉本 諭・本間基文: 金属, Vol. 69, No. 8, p. 54-61, (1999)

7) 村瀬 玩・野村武史：粉体㧍よび粉末治金, Vol. 47, No. 2, p. 179-184, (2000)

8) Kiyama, M. : Bull. Chem. Soc. Jpn., Vol. 51(1), p. 134-138, (1978)

9) Kaneko, K. and Katsura, T. : Bull. Chem. Soc. Jpn., Vol. 52(3), p. 747-752, (1979)

10) Kanzaki, T. Nakajima, J. Tamaura, Y. and Katsura, T. : Bull. Chem. Soc. Jpn., Vol. 54(1), p. 135-137, (1981)

11) Yamaura, Y. and Abe, M. : J. Colloid \& Interface Sci. Vol. 129, No. 2, p. 327-334, (1989)

12) Tamaura, Y. Sasao, T. and Abe, M. : J. Colloid \& Interface Sci., Vol. 136, No. 1, p. 242 $-248,(1990)$

13) Dias, A. and Buono, V. T. L. : J. Mater. Res., Vol. 12, No. 12, Dec., (1997)

14）辻 俊郎：電子材料, p. 70-73, Sep., (1973)

15）大野 茂: NEC 技報, Vol. 37, No. 9, p. 53-61, (1984)

16）奥田扸明・石原敏夫：NEC 技報, Vol. 37, No. 9, p. 35-42, (1984)

17）中塚勝人・小田幸人・広瀬哲也・長谷川史彦: 資源と素材, Vol. 111, p. 1027 1032, (1995)

18）平賀貞太郎・奥谷克伸・尾島輝彦：フェライト，丸善，p. 26, (1997) 